\title{
The Prevalence, Abundance, and Density of Pseudoterranova sp. (p) Larvae in the Flesh of Cod (Gadus morhua) Relative to Proximity of Grey Seal (Halichoerus grypus) Colonies on the Coast off Drangar, Northwest Iceland
}

\author{
Erlingur Hauksson \\ Marine Research Institute, Skúlagata 4, 101 Reykjavik, Iceland \\ Correspondence should be addressed to Erlingur Hauksson, erlingurhauks@simnet.is
}

Received 30 March 2011; Accepted 20 June 2011

Academic Editor: Jakov Dulčić

Copyright (C) 2011 Erlingur Hauksson. This is an open access article distributed under the Creative Commons Attribution License, which permits unrestricted use, distribution, and reproduction in any medium, provided the original work is properly cited.

\begin{abstract}
About 300 cod (Gadus morhua) were sampled on three different sites of different proximity to grey seals (Halichoerus grypus), which are the most important final host for Pseudoterranova krabbei, off Drangar, Northwest Iceland, in the summer of 2004. Cod caught at each station were grouped into four sizes: (1) $40-54 \mathrm{~cm}$, (2) $55-59 \mathrm{~cm}$, (3) $60-69 \mathrm{~cm}$ and, (4) $>70 \mathrm{~cm}$. Difference in prevalence between catch-sites were analyzed by a binary logistic regression model. Abundance, and density were investigated with multiple regressions. As expected prevalence, abundance and density of Pseudoterranova larvae were highest in the fish caught closest to shore, which was also in closest proximity to grey seal colonies and in the shallowest waters. In the closest proximity to grey seal colonies and in the shallowest water, the prevalence and abundance of sealworm larvae increased with increased length of fish. Finally, the density of Pseudoterranova larvae in cod declined exponentially with depth: $50 \%$ at 65 meters and almost zero at 210 meters. In the paper these observations were discussed in relation to sealworm eggs dispersal, depth gradient off the coast, temperature tolerance of the sealworm ovum, and behavioral types of Icelandic cod.
\end{abstract}

\section{Introduction}

Nematode infestation of cod (Gadus morhua) causes losses to fisherman and to fish merchants alike and, in consequence, necessitated special precautions, which may add considerably to the production or processing costs [1]. In Iceland the codworm (sealworm) Pseudoterranova sp. (p) is the main culprit of parasite infestation in marine fish and has to be removed from fish fillets at an annual cost of at least 10 million US\$ [2]. Similar situation is observed in other countries of the North Atlantic [3].

Grey seal (Halichoerus grypus) is considered to be the most important final host for Pseudoterranova krabbei and common seals (Phoca vitulina) for $P$. decipiens sensu stricto [4]. The larvae of P. krabbei and P. decipiens however are structurally indistinguishable and have only been identified by allozyme markers. In Icelandic waters grey seal is recognized as the main final host for Pseudoterranova larvae and common seals are believed to contribute not as much, as the grey seal, to the infestation of cod and other commercially important fish $[5,6]$. Grey seals are far more infected with Pseudoterranova $\mathrm{sp}$. ( $\mathrm{p}$ ) nematodes than common seals in Icelandic waters $[7,8]$. Even though the Icelandic common seal population is likely twice as big in numbers as the grey seal population $[9,10]$, the average Pseudoterranova burden was several times higher in grey seals than common seals, which would indicate that the relative importance of the grey seal, as a final host, is likely much higher, than that of the common seal, see [11]. The life cycle of Pseudoterranova krabbei is similar to the life cycle of $P$. decipiens, which has been described by McClelland et al. [12].

In Icelandic waters Platt [13] was the first scientist to notice how infection of cod with Pseudoterranova larvae mirrored the distribution of the grey seal along the coast. In the Oslofiord, Norway, abundance of sealworm larvae in cod was only high close to the shore inhabited by seals, but 
TABle 1: Dates of sampling of cod, locations of sampling sites (see Figure 1), and distances to nearest coastline and to the center of the breeding assemblies of grey seals (Halichoerus grypus), at Drangar off the coast of NW-Iceland.

\begin{tabular}{|c|c|c|c|c|c|}
\hline Date & Station number & Latitude and longitude & Depth $(\mathrm{m})$ & Distance to shore (km) & $\begin{array}{c}\text { Distance to center of } \\
\text { breeding assembly at } \\
\text { Drangar, NW-Iceland }(\mathrm{km})\end{array}$ \\
\hline 28 July 2004 & 1 & $66^{\circ} 05^{\prime} 90 \mathrm{~N} 21^{\circ} 34^{\prime} 48 \mathrm{~W}$ & 20 & 1.5 & 20 \\
\hline 28 July 2004 & 2 & $66^{\circ} 11^{\prime} 88 \mathrm{~N} 21^{\circ} 22^{\prime} 40 \mathrm{~W}$ & 50 & 15 & 22 \\
\hline 4 August 2004 & 3 & $66^{\circ} 42^{\prime} 14 \mathrm{~N} 21^{\circ} 17^{\prime} 97 \mathrm{~W}$ & 90 & 70 & 60 \\
\hline
\end{tabular}

TABle 2: Abundance, density, and prevalence of Pseudoterranova larvae in the four length-groups cod (Gadus morhua) from the three catch stations.

\begin{tabular}{|c|c|c|c|c|c|}
\hline Station & Length-groups $(\mathrm{cm})$ & $N$ & Abundance (SD) & $\begin{array}{l}\text { Density in kg fish } \\
\text { (SD) }\end{array}$ & Prevalence \\
\hline \multirow{4}{*}{1} & $40-54$ & 62 & $6.5(5.20)$ & $7.0(5.56)$ & 91.94 \\
\hline & $55-59$ & 18 & $12.2(22.47)$ & $9.4(18.24)$ & 94.44 \\
\hline & $60-69$ & 23 & $34.3(78.46)$ & $15.9(31.19)$ & 100.0 \\
\hline & $70+$ & 2 & $142.5(86.97)$ & 47.7 (28.77) & 100.0 \\
\hline Total & & 105 & $16.2(43.75)$ & $10.18(18.03)$ & 94.29 \\
\hline \multirow{4}{*}{2} & $40-54$ & 66 & $4.0(4.00)$ & $4.6(5.13)$ & 89.39 \\
\hline & $55-59$ & 25 & $3.7(2.75)$ & $2.7(2.03)$ & 92.00 \\
\hline & $60-69$ & 11 & $6.7(7.46)$ & $3.7(4.09)$ & 90.91 \\
\hline & $70+$ & 7 & $18.4(25.60)$ & $3.7(3.67)$ & 100.0 \\
\hline Total & & 109 & $5.16(8.14)$ & $4.03(4.38)$ & 90.83 \\
\hline \multirow{4}{*}{3} & $40-54$ & 36 & $5.0(5.39)$ & $4.5(4.86)$ & 86.11 \\
\hline & $55-59$ & 25 & $2.3(2.97)$ & $1.8(2.14)$ & 68.00 \\
\hline & $60-69$ & 27 & $3.4(3.76)$ & $1.8(2.14)$ & 85.19 \\
\hline & $70+$ & 14 & $2.5(2.65)$ & $0.8(0.92)$ & 78.57 \\
\hline Total & & 102 & $3.6(4.24)$ & $2.64(3.54)$ & 80.39 \\
\hline
\end{tabular}

farther off the abundance in cod was much lower [14, 15]. Around Scotland and northeast England infestation of cod with Pseudoterranova larvae was the highest closest to shore and in areas where the major breeding colonies of grey seals were found [16]. Aspholm et al. [17] considered common seals to be important final hosts for Pseudoterranova decipiens in Outer Oslofjord.

In Iceland, since 1973, nematode larvae in cod have been monitored on a regular basis [2]. It has been a known "fact" by people at the fish-processing plants that cod from small vessels' catch on the shallow fishing grounds close to the coast was usually much more infected with roundworms than cod caught offshore by trawlers. Spatial and bathymetric aspects of the distribution of the incidence of these larvae in cod caught in an area in northwestern Icelandic waters are presented in this paper.

\section{Material and Methods}

One of the main breeding assemblies of the Icelandic population of grey seals is on Strandir NW-Iceland, with a big concentration of animals at Drangar [18]. Common seals breed there too, but in this location they are much rarer [19]. Arrangement was made with a small-vessel fisherman on M/b Hermann Jónsson EA-18 (no. 2117), to catch cod at three different sites on the regular fishing grounds; close to the coast, as far as possible from the coast for the small boat, overall security taken into considerations, and one intermediate (Figure 1). Positions of the three fishing stations, distance from the shore, distance from Drangar, and the depth, are given in Table 1.

On board each fish was gutted and put into fish containers, one for each station $(S)$, and kept on ice. In the laboratory total length of each fish was measured $(L)$ and the fish weighed to the nearest $5 \mathrm{~g}(W)$. Otoliths were taken from each fish for aging $(A)$. The flesh of the fish was investigated for nematodes by systematic destruction on a candling table and nematodes identified to "species-groups." Results of earlier investigations on a round cod showed that systematic destruction of cod fillets on a candling table was $83.2 \%$ (95\% CI $71.9-88.2 \%$ ) as effective in revealing Pseudoterranova larvae infested the fillets, as $\mathrm{HCl}$-pepsin digestion of fish flesh (Hauksson and Olafsdóttir, unpublished). Investigations have shown that the $\mathrm{HCl}$-pepsin digestion was about $13 \%$ superior to the systematic destruction of fish fillets on a candling table in finding nematodes in cod fillets [12]. When identity of nematodes was in any doubt the nematodes were put in a mixture of $75 \%$ isopropanol, $20 \%$ water, and $5 \%$ glycerol, for later to be cleared in glycerol, mounted on slides, and identified with the use of a microscope. Prevalence $(P)$, 
Table 3: Parameter estimates, for the model of prevalence of Pseudoterranova larvae in cod (Gadus morhua) from the three catch stations. Cod from catch station 3 was used as reference point.

\begin{tabular}{|c|c|c|c|c|c|}
\hline \multirow{2}{*}{ Terms } & \multirow{2}{*}{$\beta$} & \multirow{2}{*}{ SE } & \multicolumn{2}{|c|}{ 95\% C.I. } & \multirow{2}{*}{$P$ value } \\
\hline & & & Lower & Upper & \\
\hline Constant & 6.1345 & 3.0699 & 0.1175 & 12.1515 & 0.046 \\
\hline Station 1 & 1.5181 & 0.5197 & 0.4996 & 2.5366 & 0.004 \\
\hline Station 2 & 1.0311 & 0.4624 & 0.1249 & 1.9373 & 0.026 \\
\hline Length $(L)$ & -0.2231 & 0.0886 & -0.3967 & -0.0495 & 0.012 \\
\hline Weight $(W)$ & 0.0113 & 0.0035 & 0.0044 & 0.0181 & 0.001 \\
\hline$L * W$ & -0.0001 & 0.0000 & -0.0002 & -0.0000 & 0.002 \\
\hline
\end{tabular}

TABle 4: Abundance, density and prevalence of Pseudoterranova larvae in cod (Gadus morhua) in relation to age in the three catch stations.

\begin{tabular}{|c|c|c|c|c|c|}
\hline Station & Age (years) & $N$ & Abundance (SD) & $\begin{array}{l}\text { Density in kg fish } \\
\text { (SD) }\end{array}$ & Prevalence \\
\hline \multirow{8}{*}{1} & 3 & 1 & $7.0(-)$ & $9.5(-)$ & 100.0 \\
\hline & 4 & 24 & $5.8(5.24)$ & $6.9(5.78)$ & 87.5 \\
\hline & 5 & 43 & $6.9(5.25)$ & $6.2(5.11)$ & 93.0 \\
\hline & 6 & 19 & $14.4(22.80)$ & $10.8(17.92)$ & 100.0 \\
\hline & 7 & 13 & $34.0(57.40)$ & $14.8(20.26)$ & 100.0 \\
\hline & 8 & 1 & $81.0(-)$ & $27.3(-)$ & 100.0 \\
\hline & 9 & 1 & $378(-)$ & $148.2(-)$ & 100.0 \\
\hline & 10 & 1 & $64.0(-)$ & $35.8(-)$ & 100.0 \\
\hline \multirow{8}{*}{2} & 3 & 5 & $1.6(1.52)$ & $2.3(1.74)$ & 80.0 \\
\hline & 4 & 26 & $3.6(3.06)$ & $4.0(3.57)$ & 92.3 \\
\hline & 5 & 47 & $4.5(4.39)$ & $4.6(5.62)$ & 87.2 \\
\hline & 6 & 17 & $7.1(16.08)$ & $2.8(11.54)$ & 94.1 \\
\hline & 7 & 10 & $7.4(7.15)$ & $4.1(3.89)$ & 100.0 \\
\hline & 8 & 3 & $17.7(17.67)$ & $6.0(1.78)$ & 100.0 \\
\hline & 9 & - & - & - & - \\
\hline & 10 & 1 & $6.0(-)$ & $1.9(-)$ & 100.0 \\
\hline \multirow{6}{*}{3} & 3 & 0 & - & - & - \\
\hline & 4 & 16 & $3.8(3.92)$ & $3.3(3.76)$ & 87.5 \\
\hline & 5 & 46 & $2.7(3.53)$ & $2.2(3.25)$ & 76.1 \\
\hline & 6 & 29 & $4.4(6.17)$ & $3.0(4.09)$ & 82.8 \\
\hline & 7 & 6 & $5.3(6.10)$ & $2.5(3.65)$ & 83.3 \\
\hline & 8 & 3 & $6.0(6.01)$ & $3.9(4.92)$ & 66.7 \\
\hline \multirow{8}{*}{ Total } & 3 & 6 & $2.5(2.60)$ & $3.4(1.92)$ & 83.3 \\
\hline & 4 & 66 & $4.5(4.22)$ & $4.9(4.71)$ & 89.4 \\
\hline & 5 & 136 & $4.6(4.78)$ & $4.3(5.02)$ & 85.3 \\
\hline & 6 & 65 & $8.0(15.48)$ & $5.2(10.56)$ & 90.8 \\
\hline & 7 & 29 & $18.9(40.33)$ & $8.5(14.70)$ & 96.6 \\
\hline & 8 & 7 & $21.7(28.86)$ & $8.2(9.05)$ & 85.7 \\
\hline & 9 & 1 & $378.0(-)$ & $148.2(-)$ & 100.0 \\
\hline & 10 & 2 & $35.0(41.01)$ & $18.9(24.00)$ & 100.0 \\
\hline
\end{tabular}

abundance $(X)$, and density $(T=X / W ; W$ gutted weight $)$ of Pseudoterranova larvae were defined according to [20].

Cod caught at each station was grouped into four sizes: (1) $40-54 \mathrm{~cm}$, (2) $55-59 \mathrm{~cm}$, (3) $60-69 \mathrm{~cm}$ and (4) $>70 \mathrm{~cm}$. For investigating differences in prevalence between catchsites a binary logistic regression model was used.
$(Y=S+L+W+L * W)$, where $Y=\ln (\pi /(1-$ $\pi)$ ) and $\pi$ is the probability that $Y=1$ (at least one Pseudoterranova larvae present), with catch site $(S)$ as a factor. Abundance $(X)$ and density $(T)$ of Pseudoterranova larvae in cod was investigated with multiple regression analyses, seawater depth (D) at the fishing site used instead 


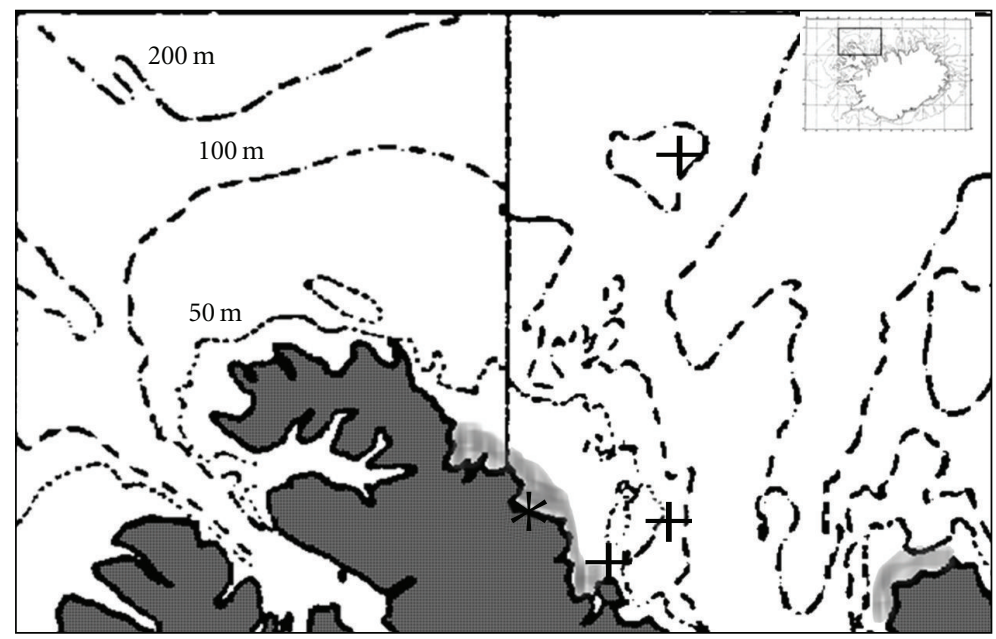

Figure 1: Location of sampling stations (+) for cod (Gadus morhua), in relation to the shoreline and the main breeding spot (black*) of grey seals (Halichoerus grypus) in the area, the general breeding distribution in the area is indicated on the figure with a shade of light grey.

of station numbers, and worm counts, $\log _{e}+1$, transformed, for bringing the frequency distribution of sealworm counts, which were positively skewed to varying degree $\left(\sigma^{2} / \hat{y}>1\right)$, closer to normality. Normality was tested by using quantilequantile plots (Q-Q plot), which show approximately normal distributed data following a straight line. Statistical analyses were done with Cytel's LogXact version 7 of the Cytel Statistical Software and Services (the binary logistic regression) and Systat 11, Systat Software, Inc. (the multiple regression).

\section{Results}

The abundance, density, and prevalence, were generally much higher at station 1, than at the other stations in most length-groups of cod (Table 2). Prevalence was significantly different between cod from the three catching sites. Cod from station 1 had significantly higher prevalence than cod from station $3(P=0.004$; Table 3$)$, and cod from station 2 were less significantly different from cod from station $3(P=0.03$; Table 3). Prevalence of Pseudoterranova larvae decreases with seawater depth and fish length, but increases with fish-age (Figure 2) and with weight of gutted cod. However this differs for cod from the three stations, because there was a significant interaction between fish length and gutted weight $(P=0.002$; Table 3$)$. The best model for the abundance $(X)$ was as follows:

$$
\begin{aligned}
\log _{e}(X+1)= & 1.888( \pm 0.833)-0.062( \pm 0.021) L \\
& +0.001( \pm 0.000) W+0.496( \pm 0.101) A \\
& +0.014( \pm 0.001) D-0.005( \pm 0.002) A * D
\end{aligned}
$$

( $\left.n=312, R_{\mathrm{ad}}^{2}=0.24\right)$. The regression model was significant $\left(F_{5,306}=20.57, P<0.0001\right)$. Abundance of Pseudoterranova larvae increases somewhat with fish length (Figure 3 ), but decreases with fish length, within age groups, and increases with fish-weight. There was a significant interaction between age and fishing depth, which makes it difficult to single out the effect of age or depth, because changes in abundance of Pseudoterranova larvae in each age class is different in relation to depth. In cod from station 1 and 2, abundance increased markedly with age of fish, however, in cod from station 3 the observed increase of abundance with age was much lower and probably not significant (Figure 3 and Table 4). For density $(T)$, the best model was as follows:

$$
\begin{aligned}
\log _{e}(T+1)= & 2.233( \pm 0.306)-0.022( \pm 0.007) L \\
& +0.191( \pm 0.055) A-0.011( \pm 0.002) D
\end{aligned}
$$

$\left(n=312, R_{\mathrm{ad}}^{2}=0.19, F_{3,308}=25.65, P<0.0001\right)$. There was no significant interaction, the density of Pseudoterranova larvae increases with fish-age, but decreases significantly with fish length within age groups of fish and decreases significantly with fishing depth (Table 4 and Figure 4).

\section{Discussion}

Prevalence, abundance, and density of Pseudoterranova larvae were highest in the fish caught closest to shore, which was also in closest proximity to grey seal colonies and in the shallowest waters. In the study area, common seals were also in considerable numbers, so their effect cannot completely be ruled out in spreading sealworm ova to the environment. Aspholm et al. [17] considered common seals to be important final hosts for Pseudoterranova decipiens in Outer Oslofjord. However, at Drangar grey seals concentrate in the autumn to breed, and big groups of grey seals are usually observed there during the summer [18]. Research has shown that grey seals are far more infected with Pseudoterranova sp. (p) nematodes than common seals in Icelandic waters $[7,8]$.

Closest to the coast, in the closest proximity to the grey seal colonies and in the shallowest waters, the prevalence and abundance of sealworm larvae increased with increased length of fish. However, farthest from the coast, and the 


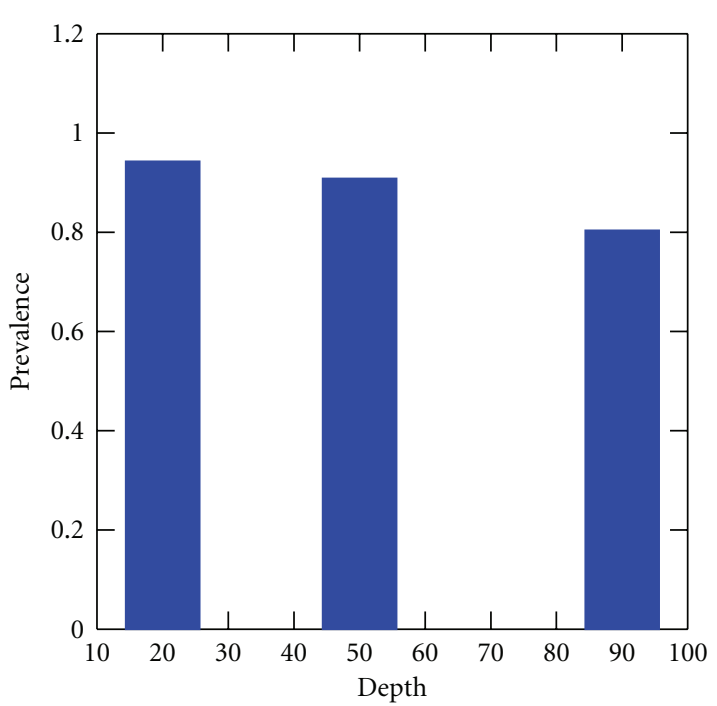

(a)

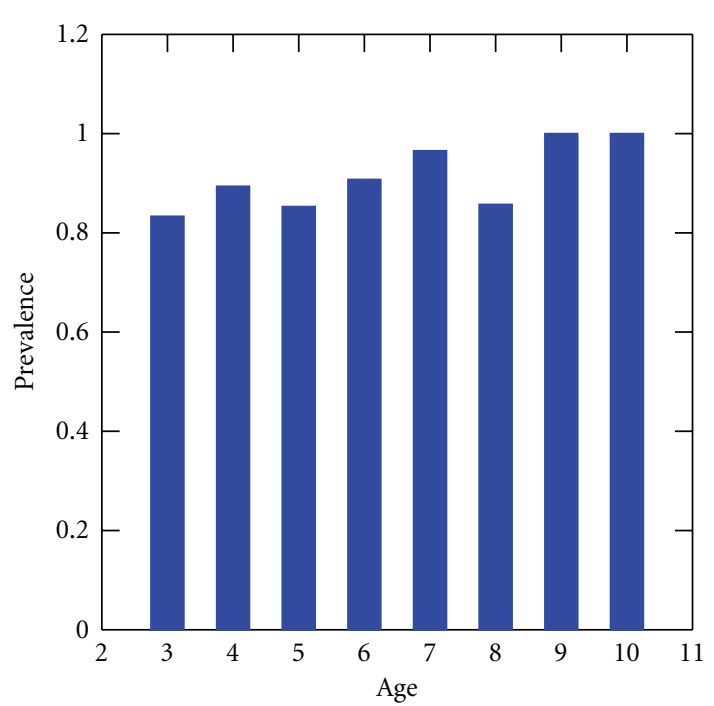

(b)

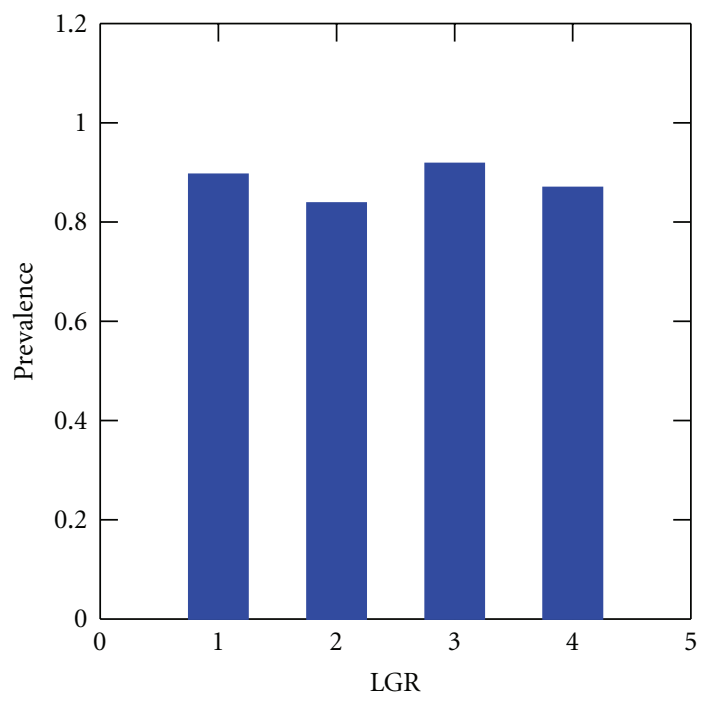

(c)

FIGURE 2: Prevalence of sealworm larvae (Pseudoterranova sp. (p)) in cod (Gadus morhua) in relation to length-groups of fish ((1) 40-54 cm, (2) $55-59 \mathrm{~cm},(3) 60-69 \mathrm{~cm}$, and $(4)>70 \mathrm{~cm})$, fish-age, and seawater depth.

grey seal breeding colonies, and in the deepest waters, the abundance decreased with fish length (Table 2). This caused probably the observed significant interaction between fish length and fish-weight in case of the prevalence, and between depth and length of cod in case of the abundance of Pseudoterranova larvae. Density of Pseudoterranova larvae decreased more regularly with depth in age and length groups of cod, than was observed for prevalence and abundance, and this relationship between density and seawater depth was not complicated with interactions between the factors in the model.

Depth of the water, rather than the distance to the coast or the proximity to the grey seal colonies was probably the controlling factor for the prevalence, abundance, and density of Pseudoterranova larvae in the cod. Of course these factors are highly correlated and all can have influence on the infection process. The grey seal colonies were the source for the Pseudoterranova larvae, and the benthic topography of the NW-Icelandic water is such that depth increases as farther you move from the coast. However, with increased depth the fragmentation of the seal feces increases, before it hits the seabed. In the shallowest waters it concentrates probably on the sea bottom. A sealworm ovum sinks in sea-water with the velocity of $0.0001 \mathrm{~m} / \mathrm{sec}$ [21]. It takes one single egg, therefore, about 28 hours to sink to 10 meters depth. In that time, 1 nautical mile $(\mathrm{nm})$ sea-water current, would transport it about $28 \mathrm{~nm}$ from the origin. Dispersal of these eggs are, therefore, immense, and dilation in the sea considerable over the deeper water. With increased distance from the shore and increased depth, concentration of sealworm eggs on the seafloor probably gets very low and the likelihood that a cod picks up infection by eating infested 


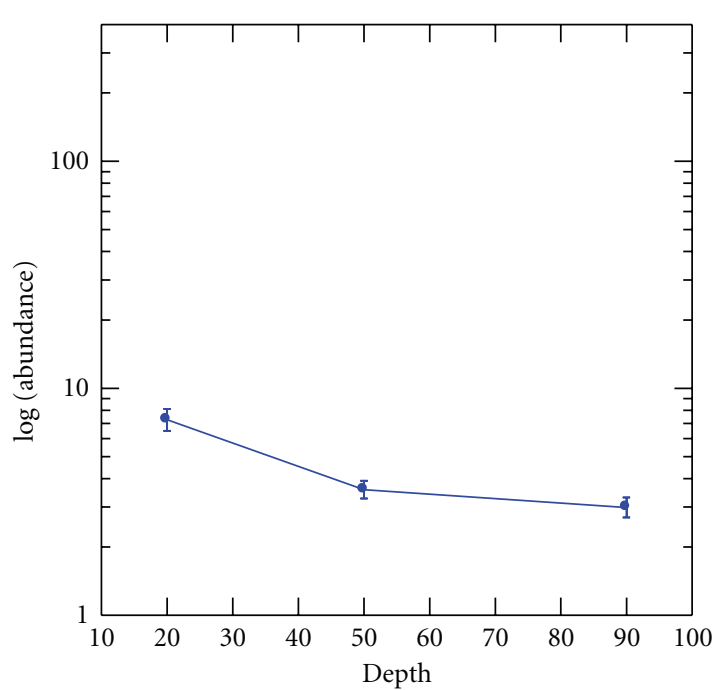

(a)

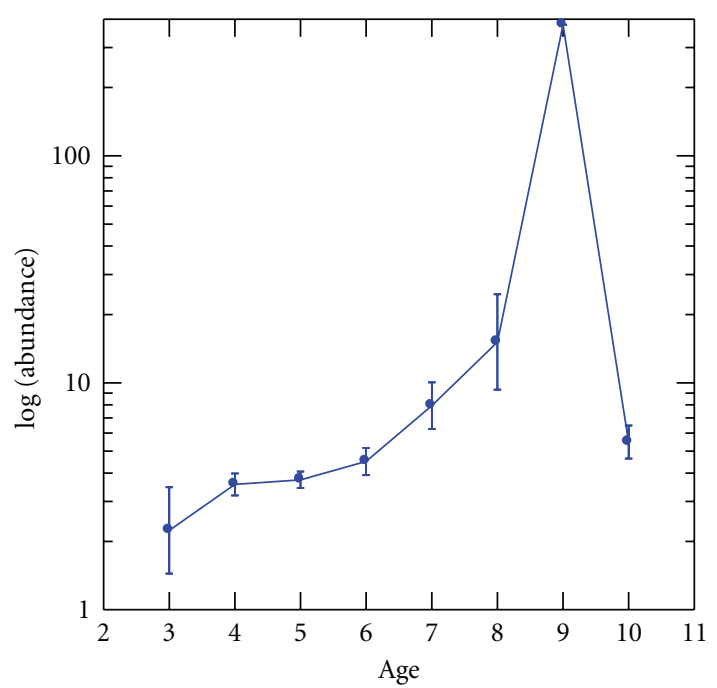

(b)

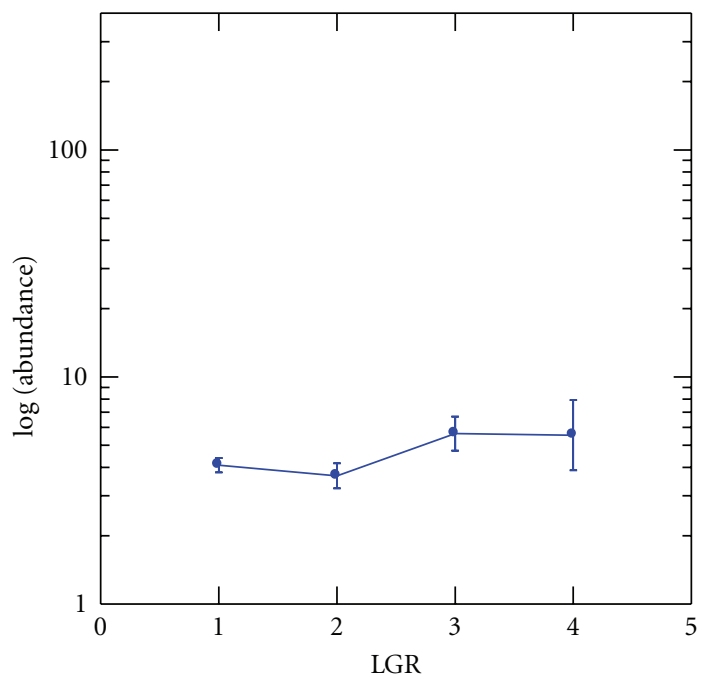

(c)

Figure 3: Abundance (logarithmic scale), of sealworm larvae (Pseudoterranova sp. (p)) in cod (Gadus morhua) in relation to length-groups of fish ((1) 40-54 cm, (2) 55-59 cm, (3) 60-69 cm and (4) >70 cm), fish-age, and sea-water depth.

intermediate host is low. In deeper water far off the coast it is also more probable that sealworm eggs could experience too low bottom temperatures to be able to hatch, $0^{\circ} \mathrm{C}$ according to [22]. On the other hand, closest to shore in shallow waters, where the seal feces sink probably intact to the bottom, the concentration of eggs could reach much higher value, and can also concentrate in intermediate hosts, and thus, the probability that cod gets infected by eating intermediate hosts is much higher there than in deeper waters. In shallow waters, the probability for the eggs to experience subzero temperatures, would also be very low, occurring only very rarely, in years of extremely heavy sea ice [23].

The results indicate that the density of Pseudoterranova larvae in cod declines approximately exponentially with depth and in the case of $60 \mathrm{~cm}$ and 7-year-old cod, as a reference, it has been reduced by $50 \%$ in depth of about 65 meters and density is particularly zero in such cod living at 210 meters depth. This means that fishing boats, as a precaution against a high number of nematodes in caught cod, should catch fish deeper than 70 meters. To select against cod with high Pseudoterranova, they should fish deeper than 200 meters. This could also be an explanation of the experience of the people from the fish-processing plants, that cod caught by trawlers, in deep waters, have much lower incidence of nematode larvae than cod caught by small boats, in shallow waters.

This observed difference in infestation of cod with sealworm larvae, in relation to fishing depth or distance from the coast, would indicate a stationary nature of cod in relation to those factors, because cod accumulate larvae in their flesh during the lifespan, and it may take years for the larvae to die and disappear from the flesh while even no larvae was ingested with the food (Hauksson unpublished). Recent observation on cod's otolith growth and shape [24], 


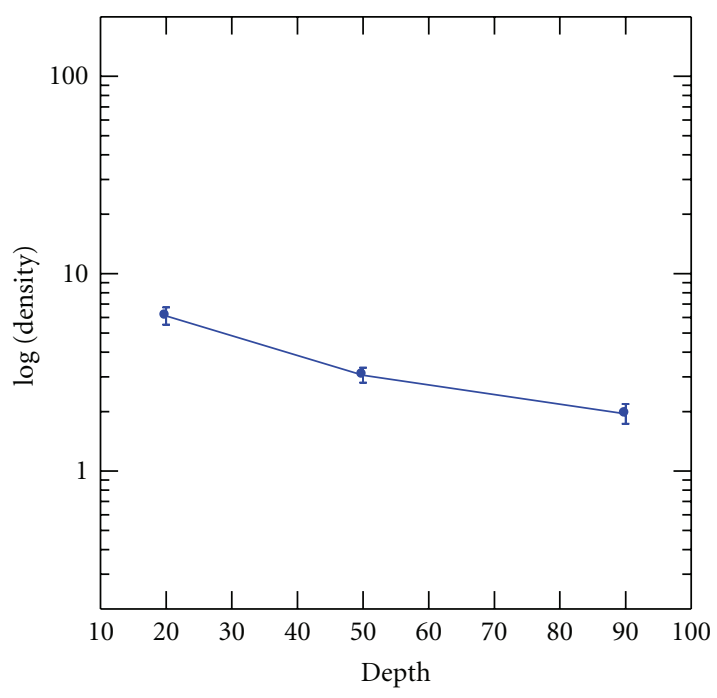

(a)

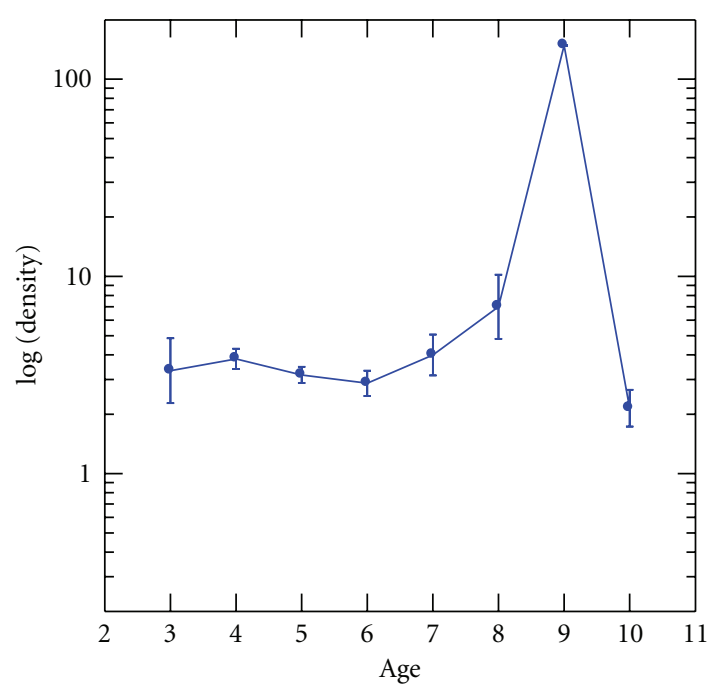

(b)

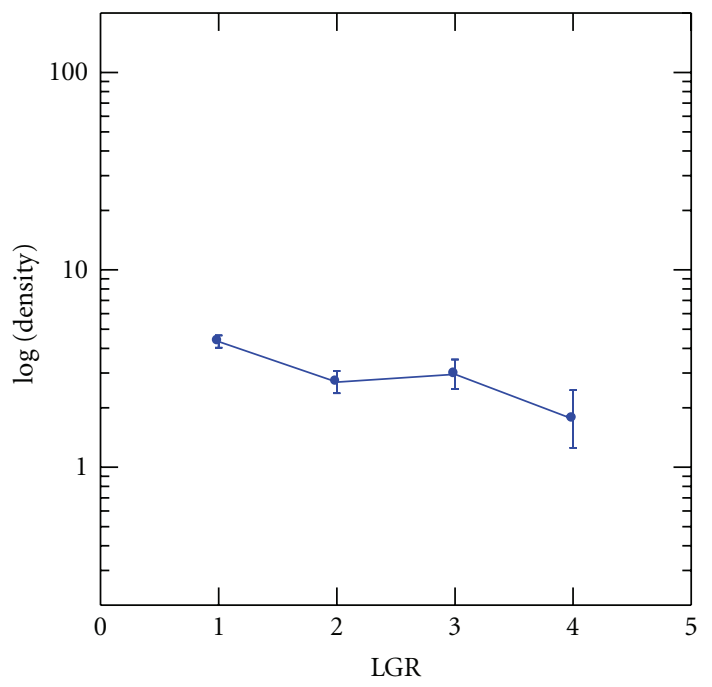

(c)

Figure 4: Density (logarithmic scale) of sealworm larvae (Pseudoterranova sp. (p)) in cod (Gadus morhua) in relation to length groups of fish ((1) 40-54 cm, (2) 55-59 cm, (3) 60-69 cm and (4) $>70 \mathrm{~cm})$, fish-age, and sea-water depth.

migration patterns, by using data storage tags [25], and genetics, by investigating the Pan I locus [26] of Icelandic cod indicate that fish can be classified into deep-water and shallow water behavioral types, that either forage and stay mainly in shallow water, or migrate to deeper and colder waters foraging at thermal fronts and going to shallowwater only for breeding. Such different behavior of cods would probably cause quite a difference in sealworm burden between the cod types.

\section{Acknowledgments}

Mr. Gunnsteinn Gislason, merchant, helped out in organizing the sampling of the cod, and Mr. Hrafn Jonsson, fisherman, collected the cod after directions from the author.
Fisheries and fish sale organizations of Iceland sponsored this research.

\section{References}

[1] B. B. Rae, "A review of the cod-worm problem in the North Sea and in Western Scottish waters 1958-1970," Marine Research, vol. 1972, no. 2, pp. 1-24, 1972.

[2] E. Hauksson and G. Valdimarsson, "Monitoring of parasites," in Fish Inspection, Quality Control, and HACCP. A Global Focus, R. E. Martin, R. L. Collette, and J. W. Slavin, Eds., pp. 277-289, Technomic, Lancaster, UK, 1997.

[3] G. McClelland, "The trouble with sealworms (Pseudoterranova decipiens species complex, Nematoda): a review," Parasitology, vol. 124, pp. S183-S203, 2002.

[4] L. Paggi, S. Mattiucci, D. I. Gibson et al., "Pseudoterranova decipiens species A and B (Nematoda, Ascaridoidea): 
nomenclatural designation, morphological diagnostic characters and genetic markers," Systematic Parasitology, vol. 45, no. 3, pp. 185-197, 2000.

[5] D. Olafsdóttir, "Review of the ecology of sealworm, Pseudoterranova sp. (p) (Nematoda: Ascaridoidea) in Icelandic waters," NAMMCO Scientific Publications, vol. 3, pp. 95-111, 2001.

[6] E. Hauksson, "Nematode infestation and diet of fish, cormorants (Phalacrocorax carbo) and common seals (Phoca vitulina) at Melrakkanes, Hamarsfjördur, Eastern Iceland," Marine Research Institute Report, vol. 115, no. 1, pp. 21-30, 2005 (Icelandic).

[7] D. Ólafsdóttir and E. Hauksson, "Anisakid (Nematoda) infestations in Icelandic grey seals (Halichoerus grypus Fabr.)," Journal of Northwest Atlantic Fishery Science, vol. 22, pp. 259269, 1997.

[8] D. Ólafsdóttir and E. Hauksson, "Anisakid nematodes in the common seal (Phoca vitulina L.) in Icelandic waters," Sarsia, vol. 83, no. 4, pp. 309-316, 1998.

[9] E. Hauksson, "Growth and reproduction in the Icelandic common seal (Phoca vitulina L., 1758)," Marine Biology Research, vol. 2, no. 1, pp. 59-73, 2006.

[10] E. Hauksson and S. T. Einarsson, "Review on utilization and research on harbour seals (Phoca vitulina) in Iceland," NAMMCO Scientific Publications, vol. 8, pp. 341-354, 2010.

[11] F. Aznar, J. Balbuena, M. Fernández, and J. Raga, "Establishing the relative importance of sympatric definitive hosts in the transmission of the sealworm, Pseudoterranova decipiens: a host community approach," NAMMCO Scientific Publications, vol. 3, pp. 161-171, 2003.

[12] G. McClelland, R. Misra, and D. Martell, "Larval anisakine nematodes in various fish species from Sable Island bank and vicinity," in Population Biology of Sealworm (Pseudoterranova decipiens) in Relation to Its Intermediate and Seal Hosts, W. Bowen, Ed., vol. 222 of Canadian Bulletin of Fisheries and Aquatic Sciences, pp. 83-118, 1990.

[13] N. Platt, "Infestation of cod (Gadus morhua L.) with larvae of codworm (Terranova decipiens Krabbe) and herringworm, Anisakis sp. (Nematoda Ascaridata), in North Atlantic and Arctic waters," Journal of Applied Ecology, vol. 12, pp. 437-450, 1975.

[14] T. Jensen and K. Idås, "Infection with Pseudoterranova decipiens (Krabbe, 1878) larvae in cod (Gadus morhua) relative to proximity of seal colonies," Sarsia, vol. 76, pp. 227-230, 1992.

[15] T. Jensen, K. Andersen, and S. des Clers, "Sealworm (Pseudoterranova decipiens) infections in demersal fish from two areas in Norway," Canadian Journal of Zoology, vol. 72, no. 4, pp. 598-608, 1994.

[16] B. B. Rae, "The incidence of larvae of Porrocaecum decipiens in the flesh of cod," Marine Research, vol. 1963, no. 2, pp. 1-28, 1963.

[17] P. E. Aspholm, K. I. Ugland, K. A. Jødestøl, and B. Berland, "Sealworm (Pseudoterranova decipiens) infection in common seals (Phoca vitulina) and potential intermediate fish hosts from the outer Oslofjord," International Journal for Parasitology, vol. 25, no. 3, pp. 367-373, 1995.

[18] E. Hauksson, "Abundance of grey seals in Icelandic waters, based on trends of pup-counts from aerial surveys," NAMMCO Scientific Publications, vol. 6, pp. 85-97, 2007.

[19] E. Hauksson, "Monitoring trends in the abundance of harbour seals (Phoca vitulina) in Icelandic waters," NAMMCO Scientific Publications, vol. 8, pp. 227-244, 2010.

[20] A. O. Bush, K. D. Lafferty, J. M. Lotz, and A. W. Shostak, "Parasitology meets ecology on its own terms: Margolis et al. revisited," Journal of Parasitology, vol. 83, no. 4, pp. 575-583, 1997.

[21] C. J. McConnell, D. J. Marcogliese, and M. W. Stacey, "Settling rate and dispersal of sealworm eggs (Nematoda) determined using a revised protocol for myxozoan spores," Journal of Parasitology, vol. 83, no. 2, pp. 203-206, 1997.

[22] L. N. Measures, "Effect of temperature and salinity on development and survival of eggs and free-living larvae of sealworm (Pseudoterranova decipiens)," Canadian Journal of Fisheries and Aquatic Sciences, vol. 53, no. 12, pp. 2804-2807, 1996.

[23] "Environmental conditions and plankton communities in 2004 and long-term changes," Marine Research Institute Report, vol. 116, pp. 9-18, 2005 (Icelandic).

[24] G. Petursdottir, G. A. Begg, and G. Marteinsdottir, "Discrimination between Icelandic cod (Gadus morhua L.) populations from adjacent spawning areas based on otolith growth and shape," Fisheries Research, vol. 80, no. 2-3, pp. 182-189, 2006.

[25] O. K. Pálsson and V. Thorsteinsson, "Migration patterns, ambient temperature, and growth of Icelandic cod (Gadus morhua): evidence from storage tag data," Canadian Journal of Fisheries and Aquatic Sciences, vol. 60, no. 11, pp. 1409-1423, 2003.

[26] E. Árnason, U. B. Hernandez, and K. Kristinsson, "Intense habitat-specific fisheries-induced selection at the molecular Pan I locus predicts imminent collapse of a major cod fishery," PLoS ONE, vol. 4, no. 5, Article ID e5529, 2009. 

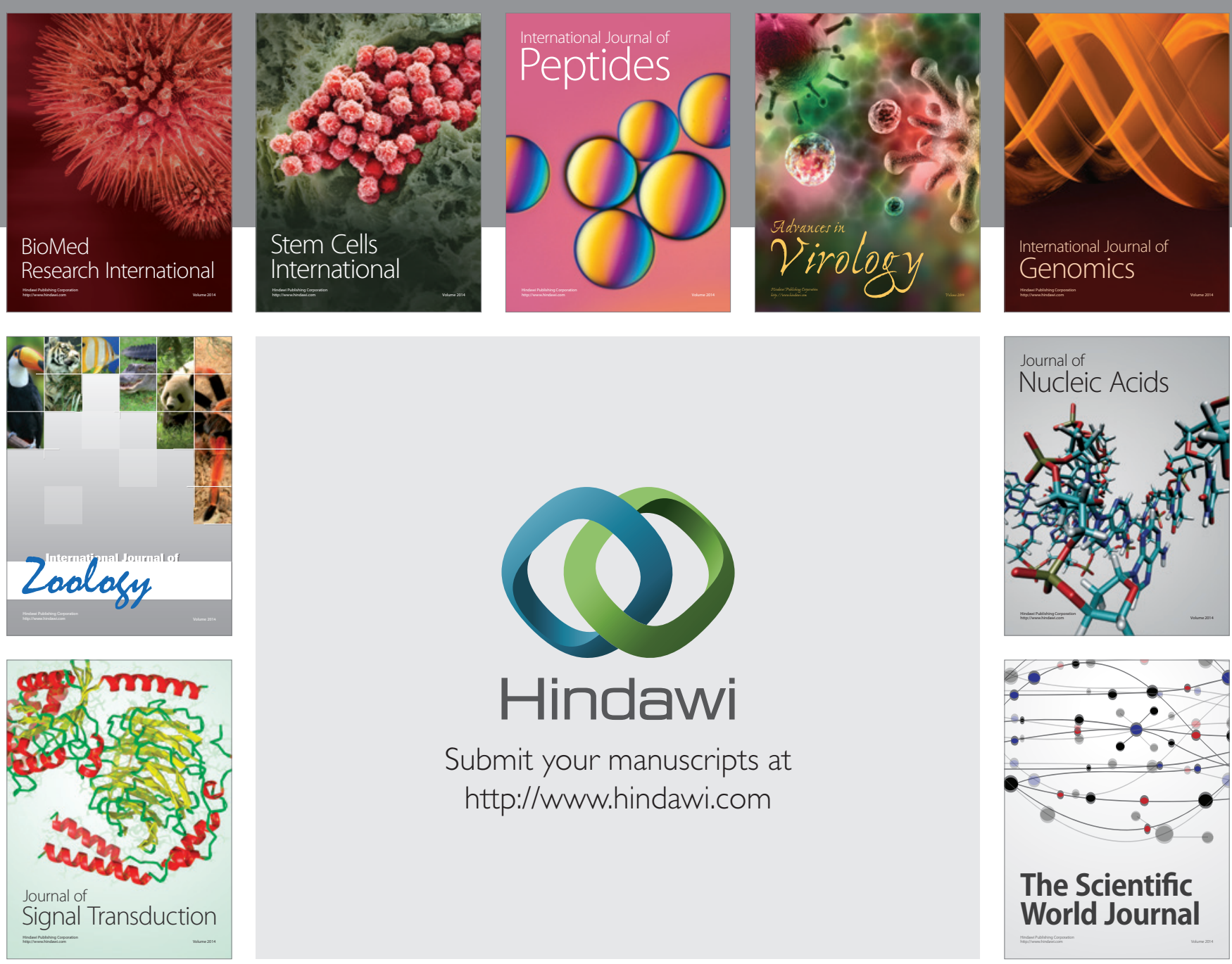

Submit your manuscripts at

http://www.hindawi.com
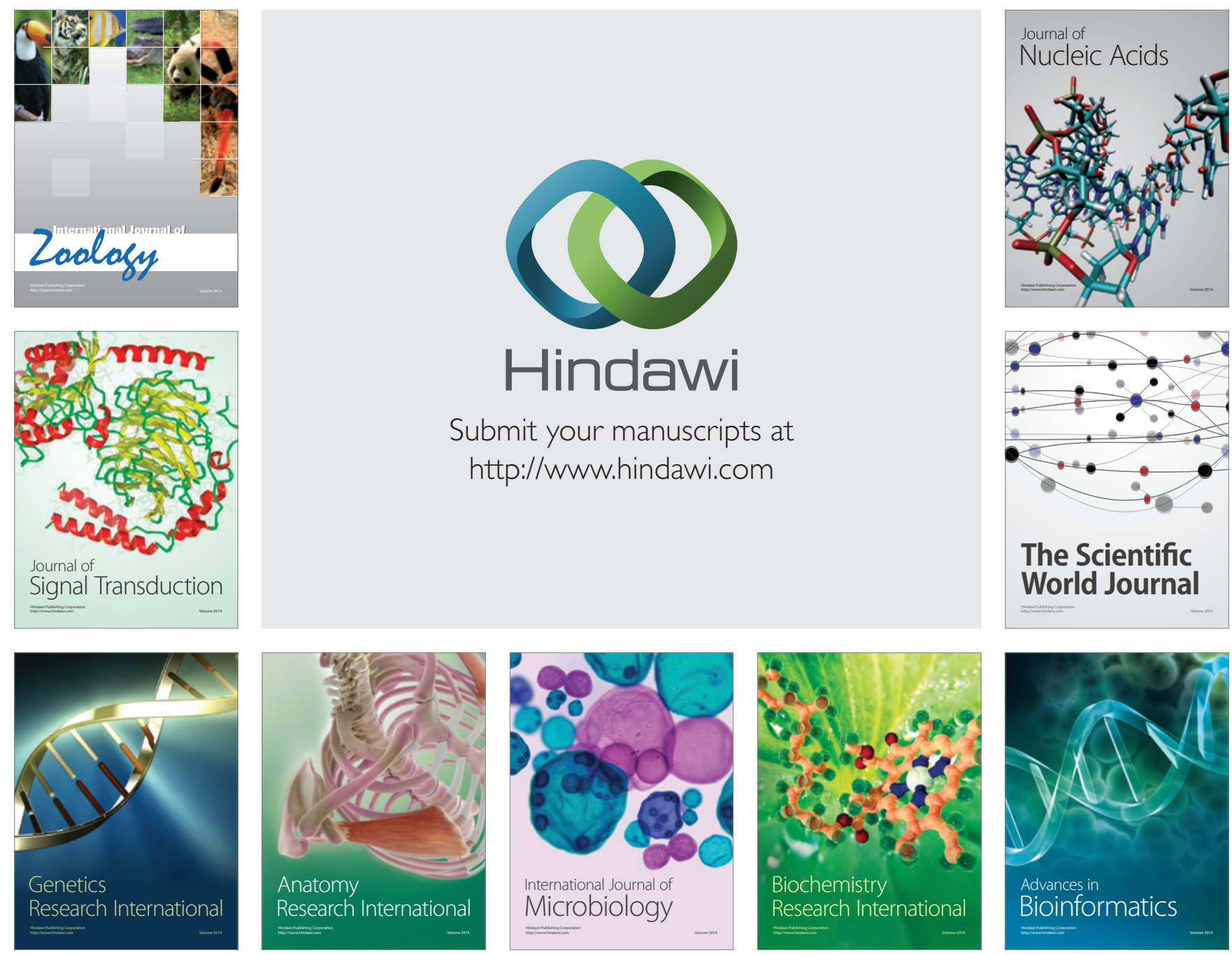

The Scientific World Journal
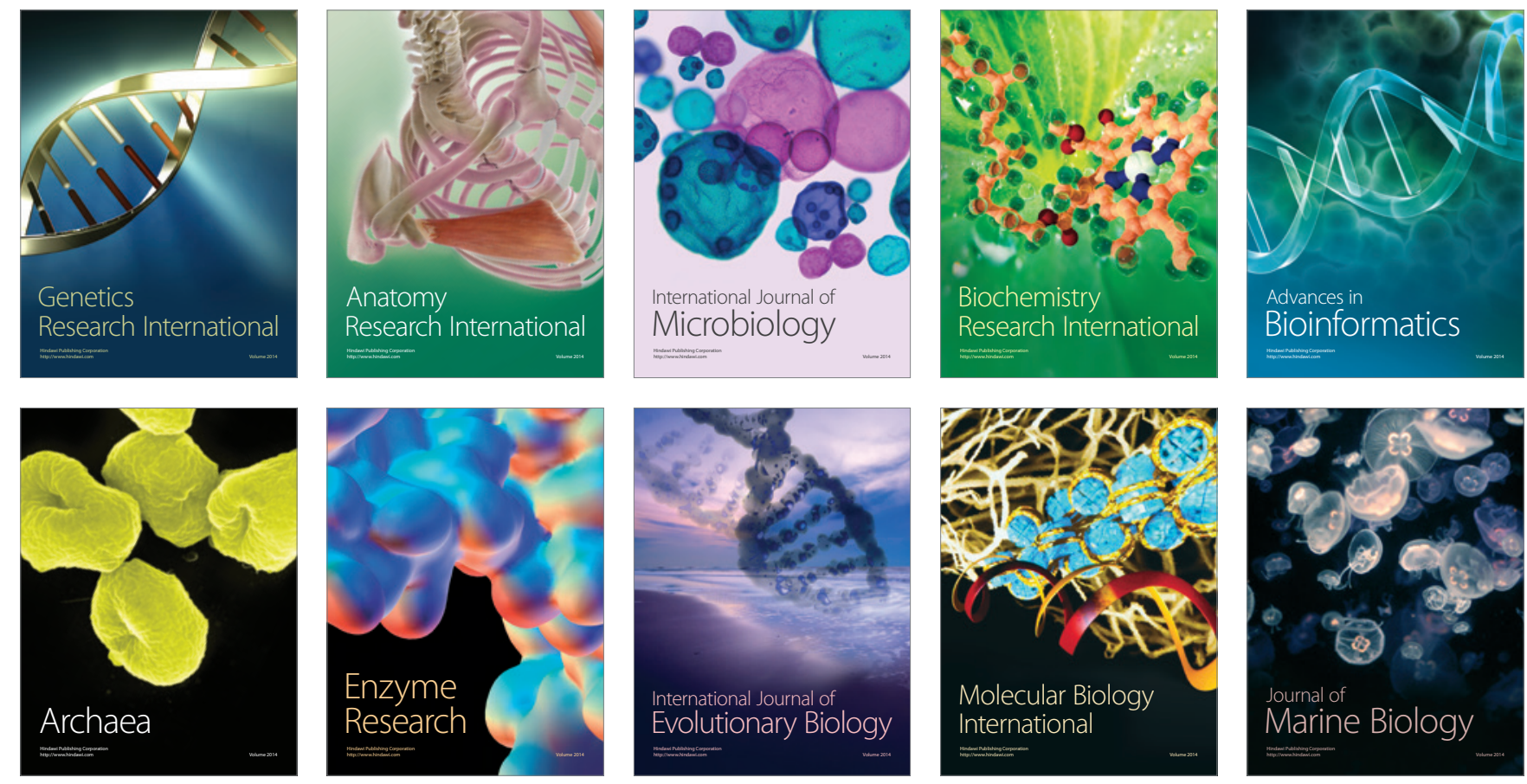